\title{
Malrotation of Intestine with Carcinoma Colon in Adult
}

\author{
Dipankar Ray, 'Gautam Chattopadhyay, 'Surajit Das' \\ 'Department of Surgical Gastroenterology, Medical College Kolkata, West Bengal Health University, Kolkata, West Bengal, \\ India.
}

\section{ABSTRACT}

Malrotation of gut is a congenital anomaly and patients usually present in childhood. Occasionally it may present in adulthood. Patients are usually asymptomatic when malrotation of gut is detected during investigations or operation. Also, it can cause longstanding abdominal symptoms and volvulus of gut. Rarely malrotation of gut may present with gastrointestinal neoplasm. We present a 60 year old female with carcinoma caecum along with intestinal malrotation.

Keywords: adult intestinal malrotation; colon cancer; gastrointestinal cancer.

\section{INTRODUCTION}

Intestinal malrotation is a congenital anomaly presenting in first few months of life. Usually it present with acute bowel obstruction and midgut volvulus. Rarely, it may present in adulthood with different abdominal problems. This report describes a case of iron deficiency anaemia and dyspepsia which, on investigation, was found to have carcinoma caecum. On laparotomy, the coexisting malrotation of gut was detected.

\section{CASE REPORT}

A 60 year old lady presented to our department with abdominal pain, dyspepsia and constipation for more than five years. Her symptoms worsened in last six months. She was hospitalized, had blood transfusion for anaemia without further investigations. Her symptoms persisted and she developed anorexia.
Physical examination revealed anaemia, abdominal fullness with mild tenderness but without any mass. Complete haemogram was suggestive of iron deficiency anaemia with $\mathrm{Hb} 6 \mathrm{gm} \%$. Biochemical reports, abdominal USG and upper GI endoscopy were unremarkable. Colonoscopy showed ulceroproliferative growth in the ascending colon. Colonoscopic biopsy diagnosed adenocarcinoma. Contrast enhanced computer tomography (CECT) of abdomen showed distended and thick walled distal small bowel and mesenteric lymphadenopathy without any mass.

On laparotomy, intestinal malrotation with Ladd's bands, thickened distal ileum with mesenteric lymph nodes along with mass in the caecum was found, which was mobile and in the midline (Figure 1).

Correspondence: Dr. Dipankar Ray, Department of Surgical Gastroenterology, Medical College Kolkata, West Bengal Health University, Kolkata, West Bengal, India. Email:dray3453@yahoo.co.in, Phone: 9830170500 . 


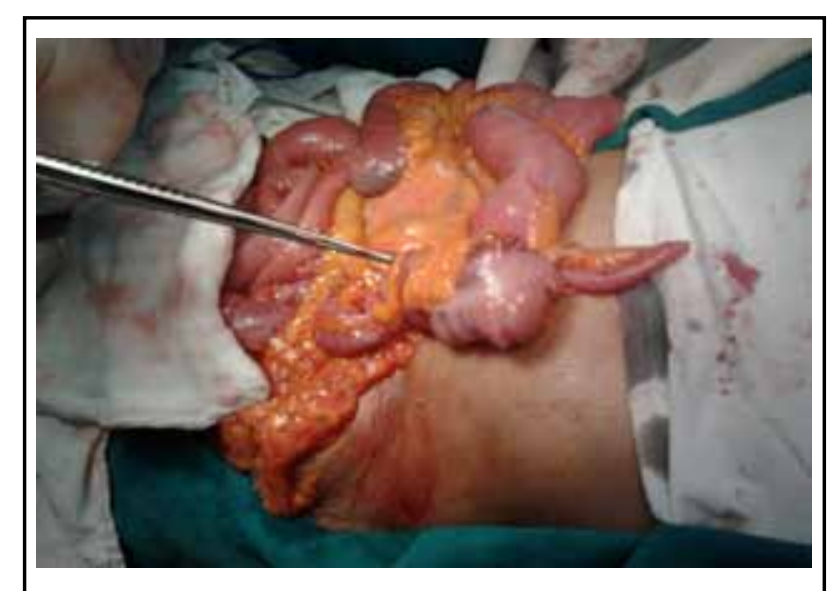

Figure 1. Intestinal malrotation with mass in the caecum in the midline with thickened and distended terminal ileum.

Adhesionolysis with release of Ladd's bands, straightening of duodenojejunal junction and broadening of mesenteric base was done. After that right hemicolectomy was done taking care of anomalous superior mesenteric vessels. Histopathology report was moderately differentiated, infiltrating adenocarcinoma caecum with metastasis in one of 22 pericaecal lymph nodes $(\mathrm{p} T 3 \mathrm{~N} 1 \mathrm{Mx})$. Patient recovered well and had postoperative chemotherapy.

\section{DISCUSSION}

Malrotation of gut is a congenital anomaly. By fifth intrauterine week, vascular pedicle develop in the developing gut. The midgut supplied by superior mesenteric vessel elongates faster than the rest of the gut and herniates out of small intraabdominal coelom. The staged return of midgut within abdominal cavity involves rotation and fixation which can be anomalous in different stages leading to malrotation of gut.

Stage 1: Failure of intestine to return to the abdominal cavity leading to exomphalos.

Stage 2: Anomalies include nonrotation, malrotation and reversed rotation (regarding $270^{\circ}$ rotation of midgut in the abdominal cavity).

Stage 3: Anomalies include an unattached duodenum, mobile caecum and an unattached small bowel mesentery. ${ }^{1}$

Midgut malrotation has been estimated to occur in one in 500 live births and majority (64-80\%) present in the neonatal period. ${ }^{2}$ Rarely, it may present in adults with variety of chronic abdominal symptoms. Many cases are asymptomatic or present with acute or chronic intestinal obstruction. $^{3}$

It may present with volvulus more commonly of ileocaecal region. Interestingly malrotation of gut in adults have been found to be associated with different gastrointestinal tumours like carcinoma stomach, carcinoma gallbladder, cholangiocarcinoma and colorectal cancers. ${ }^{2}$ So far about ten cases of colorectal cancers have been reported in adult malrotation of gut (Table 1).

Table 1. Incidences of colorectal cancers in malrotation of intestine in adults.

\begin{tabular}{|c|c|c|c|c|}
\hline $\begin{array}{l}\text { Citations including country and } \\
\text { year }\end{array}$ & Age & Sex & $\begin{array}{l}\text { Malignancy associated with } \\
\text { malrotation }\end{array}$ & $\begin{array}{l}\text { Anomalies along with } \\
\text { malrotation }\end{array}$ \\
\hline Bruna J Czech , $1970^{4}$ & NA & NA & NA & \\
\hline Gilbert HW et al, UK, $1990^{3}$ & 55 & Male & Carcinoma left colon & \\
\hline $\begin{array}{l}\text { Torreggiani WC et al, Canada, } \\
2001^{5}\end{array}$ & 86 & Female & Carcinoma caecum & \\
\hline Iwamura T et al, Japan, $2001^{6}$ & 71 & Female & $\begin{array}{l}\text { Carcinoma rectum with } \\
\text { carcinoma stomach }\end{array}$ & $\begin{array}{l}\text { Situs inversus totalis, } \\
\text { polysplenia }\end{array}$ \\
\hline Ren PT, Lu BC, China, $2009^{2}$ & 45 & Male & Carcinoma right colon & \\
\hline $\begin{array}{l}\text { Antonio Brillantino et al, Italy, } \\
2009^{7}\end{array}$ & 34 & Male & Carcinoma right colon & \\
\hline $\begin{array}{l}\text { Michalopoulos A et al, Greece, } \\
2010^{8}\end{array}$ & 76 & Male & Carcinoma ascending colon & \\
\hline Petrou A et al, Greece, $2010^{9}$ & 59 & Male & $\begin{array}{l}\text { Mucinous adenocarcinoma } \\
\text { appendix }\end{array}$ & Situs inversus totalis \\
\hline Morimoto M et al, Japan, $2012^{10}$ & 57 & Male & Carcinoma caecum & \\
\hline
\end{tabular}


Most of them involved right or ascending colon. Malrotation of gut which may cause chronic bowel obstruction may lead to inflammation and carcinogenesis. ${ }^{2}$ Whether change in composition of bile due to altered entero-hepatic circulation lead to colon cancers also remains to be investigated.
Our case of carcinoma caecum with malrotation of gut presenting as incomplete bowel obstruction and anaemia in a 60 year old lady is probably the first reported case from India.

\section{REFERENCES}

1. Sözen S, Güzel K. Intestinal malrotation in an adult: case report. Turkish Journal of Trauma and Emergency Surgery. 2012;18(3):280-2.

2. Ren PT, $\mathrm{Lu}$ BC. Intestinal malrotation associated with colon cancer in an adult: report of a case. Surg Today. 2009;39(7):624-7.

3. Gilbert HW, Armstrong CP, Thompson MH. The presentation of malrotation of the intestine in adults. Ann R Coll Surg Engl. 1990 Jul;72(4):239-42.

4. Bruna J. Simultaneous occurrence of nonrotation and intestinal cancer. Cesk Radiol. 1970 Mar;24(2):87-9.

5. Torreggiani WC, Thornton F, Lyburn I, Brenner C, Lee MJ. Malrotation of the bowel resulting in a left-sided caecal carcinoma presenting as a palpable intrahernial mass. Australas Radiol. 2001;45:362-4.
6. Iwamura T, Shibata N, Haraguchi $Y$, Hisashi $Y$, Nishikawa T, Yamada $\mathrm{H}$, et al. Synchronus double cancer of the stomach and rectum with situs inversus totalis and polysplenia syndrome. J Clin Gastroenterol. 2001Aug;33(2):148-53.

7. 7. Brillantino A, Marano L, Schettino M, Torelli F, Giuseppeizzo, Cosenza A, et al. Report of a rare case of colon cancer complicated by anomalies of intestinal rotation and fixation : a case report. Cases J. 2009 Sep 14;2:6555.

8. 8. Michalopoulos A, Papadopoulos V, Paramythiotis D, Papavramidis T, Douros V, Netta S, et al. Colonic cancer in a patient with intestinal malrotation: a case report. Tech Coloproctol. 2010 Nov;14 Suppl 1:S65-6.

9. 9. Petrou A, Papalambros A, Katsoulas N, Bramis K, Evangelou K, Felekouras E. Primary appendiceal mucinous adenocarcinoma alongside with situs inversus totalis: a unique clinical case. World J Surg Oncol. 2010 Jun 4;8:49.

10. 10.Morimoto M, Horie H, Kumano H, Lefor A, Utano K, Yasuda Y. Reversed intestinal malrotation with concurrent cecal carcinoma. Asian J Endosc Surg. 2012 Aug;5(3):149-51. 